\title{
Effect of high-intensity interval training and pre-meal water consumption on lipid profile in overweight and obese students
}

\author{
Nazhif Gifari ${ }^{1,2^{\star}}$, Hardinsyah ${ }^{2}$, Drajat Martianto ${ }^{2} \&$ Mury Kuswari ${ }^{1}$ \\ ${ }^{1}$ Department of Nutrition, Faculty of Health Sciences, Universitas Esa Unggul, \\ Jakarta, Indonesia; ${ }^{2}$ Department of Community Nutrition, Faculty of Human Ecology, \\ IPB University, Bogor, Indonesia
}

\begin{abstract}
Introduction: Obesity and overweight in adolescents and adults are associated with chronic diseases. The objective of this study was to determine the effect of high-intensity interval training and pre-meal water intake on the lipid profile of overweight and obese students. Methods: This was a pre-post experimental study. Twenty-seven overweight and obese students (mean BMI $26.0 \pm 3.1 \mathrm{~kg} / \mathrm{m}^{2}$ and mean age 19.7 \pm 0.7 years) were divided randomly into three groups. The first group $(n=9$; $\mathrm{BMI}=26.6 \pm 3.6 \mathrm{~kg} / \mathrm{m}^{2}$ ) received Plain Water Intake (PWI) intervention, whereby students received three bottles of plain water $(600 \mathrm{~mL})$ per mealtime (total $1.8 \mathrm{~L}$ / day) and consumed ad libitum 30 to 45 minutes before mealtime (breakfast, lunch, and dinner). The second group $\left(n=9 ; \mathrm{BMI}=25.9 \pm 2.4 \mathrm{~kg} / \mathrm{m}^{2}\right)$ received High-Intensity Interval Training (HIIT) intervention and underwent three exercise sessions per week (18 minutes/day; $70-85 \%$ of HRmax) that was introduced through a video recording. The last group $\left(n=9 ; \mathrm{BMI}=25.7 \pm 3.4 \mathrm{~kg} / \mathrm{m}^{2}\right)$ received a combination of PWI+HIIT intervention. Nutritional status, nutrient intake, and lipid profile [total cholesterol (TC), triglycerides (TG), high-density lipoprotein cholesterol (HDL-C), and low-density lipoprotein cholesterol (LDL-C)] were assessed before and after the interventions. Data were analysed using paired sample $t$-test and Analysis of Variance (ANOVA). Results: The PWI group showed a significant increase in HDL-C, while the HIIT group showed a significant reduction in TC $(p<0.05)$. On the other hand, the PWI+HIIT group showed significant improvements in lipid profile (TC, TG and HDL-C) $(p<0.05)$. Conclusion: A combination of PWI+HIIT intervention may be effective in improving lipid profile.
\end{abstract}

Keywords: High-Intensity Interval Training; lipid profile; water consumption

\section{INTRODUCTION}

Overweight is a global public health problem that has a negative impact on health. Obesity has become a risk factor for various degenerative diseases, such as coronary heart disease, type 2 diabetes mellitus and osteoarthritis (Aronne \& Isoldi, 2007). The prevalence of overweight has increased in recent years. Therefore, many efforts are required to keep weight within the normal range. In 2016, there were 39\% of adults (39\% men and 40\% women) who experienced overweight and 13\% who were obese; meanwhile, over 340 million children and adolescents were overweight and obese (WHO, 2016).

\footnotetext{
*Corresponding author: Nazhif Gifari

Department of Nutrition, Faculty of Health Sciences, Universitas Esa Unggul

Email: nazhif.gifari@esaunggul.ac.id; nazhif27@gmail.com

doi: https://doi.org/10.31246/mjn-2020-0034
} 
Based on the data taken from the Indonesian National Basic Health Research (RISKESDAS) in 2018, the prevalence of obesity in adult men and women in Indonesia were $21.8 \%$ (NIHRD, 2018). The prevalence has increased when compared with data from the same resources in 2007 and 2013 (NIHRD, 2018). Some of the causes of overweight and obesity are high consumption of energy-dense foods and lack of physical activity (Popkin, Adair \& Ng, 2017).

A combination of exercise and diet is the most effective way to optimise improvement in nutritional status (Gaesser, Angadi, \& Sawyer, 2011). Previous research has shown that regular aerobic exercise can improve cardiometabolic risk profile such as increasing high-density lipoprotein cholesterol (HDL-C) levels and decreasing the levels of total cholesterol (TC), lowdensity lipoprotein cholesterol (LDL-C), and triglycerides (TG) (Süel, 2013). One of the exercises that can help in lipid profile management is High-Intensity Interval Training (HIIT) (Gripp et al., 2020). HIIT is a cardio exercise that can improve fitness and maintain body composition through short duration, high-intensity trainings (Kessler, Sisson, \& Short, 2012).

Consuming adequate amount of water is highly recommended as one of the efforts to maintain and control weight. Studies have shown that regular water consumption provides metabolic stimulation, such as the thermogenesis process (Buschmann et al., 2003). A previous study showed that the consumption of plain water was associated with weight loss and decreased energy intake (Stookey et al., 2007). Another study indicated that overweight and obese adult subjects lost weight by consuming two cups $(500 \mathrm{~mL})$ of plain water 1-2 hours before mealtime (lunch and dinner) (Dennis et al., 2011). Therefore, taking pre-meal water to reduce meal energy intake can be an effective weight control strategy (Jeong, 2018).

Based on these several studies, the researchers of this study were interested in studying the combination of plain water intake (PWI) and HIIT intervention, and their effects on lipid profile (TC, TG, HDL-C, and LDL-C). This study aimed to analyse the efficacy of HIIT, premeal water consumption (PWI), and a combination of both interventions on lipid profile in overweight and obese students.

\section{MATERIAL AND METHODS}

\section{Design and subjects}

The study was a pre-post experimental study with three intervention groups. This research was conducted from October 2014 to April 2015 at the Sport Nutrition and Nutritional Status Laboratory, IPB University. Participants were recruited from the student population at IPB University, Indonesia. Twenty-seven overweight and obese students (five men and 22 women) were randomly selected to participate in this study. Inclusion criteria were: Individuals who were (a) overweight and obese with a body mass index (BMI) $\geq 25 \mathrm{~kg} / \mathrm{m}^{2}$, (b) aged 18-23 years, and (c) not active smokers. The exclusion criteria were those who: (a) consumed weight loss supplement(s), (b) consumed alcohol, and (c) suffered from illnesses. All subjects willingly participated in the study by signing a prepared informed consent form. The study protocol was approved by the Ethics Committee of the Faculty of Medicine, University of Indonesia (Number 572/UN2.F1/ ETHICS/2015).

\section{Measurement of anthropometric and biochemical indices}

Anthropometric measurements included body weight $(\mathrm{kg})$, height $(\mathrm{cm})$, body mass index $(\mathrm{BMI})\left(\mathrm{kg} / \mathrm{m}^{2}\right)$, percentage of body 
fat (\%), and total body water (TBW). Body weight $(\mathrm{kg})$ was measured by Vakind ${ }^{\circledR}$ Portable scale, while BMI $\left(\mathrm{kg} / \mathrm{m}^{2}\right)$ and percent body fat (\%) were measured by Body Composition Monitor Omron (HBF-516B). Venous blood samples were collected in the morning (07.00-08.00 am) by specialised nurses, after 8-12 hours of fasting. Lipid profile components consisting of TC, TG, HDL-C, and LDL-C were measured by using the enzymatic calorimetric method (Cholesterol CHODPAP and Triglycerides GPO-PAP).

\section{Nutrient intake}

Dietary intake was recorded at week 0 and week 8 for two days each week (on weekend and weekday) using a 24hour dietary recall. Habitual beverage consumption was estimated by a registered nutritionist utilising a food frequency questionnaire. Beverage intake during the intervention was divided into water intake and energy intake from carbonated drinks, electrolytes drinks, coffee or tea, juice or fruit juice, and milk. Nutrition composition such as energy, protein and fat was assessed before and after the interventions. This study employed the Indonesian Food Composition Table (TKPI) to calculate for nutrients intake from foods and beverages.

\section{Intervention}

The duration of intervention administered for each group was two months. Different treatments were given for each group: pre-meal water consumption (PWI group, $n=9$ ) in the first group, HIIT (HIIT group, $n=9$ ) in the second group, and a combination of PWI and HIIT (PWI+HIIT group, $n=9$ ) in the third group. PWI intervention was given to subjects by managing the pattern of plain water consumption; that was, drinking a 600 $\mathrm{mL}$ bottle before each mealtime with a total water intake of $1.8 \mathrm{~L} /$ day despite the fact that $1.5 \mathrm{~L} /$ day, $30-50$ minutes before each meal has been regarded as effective (Davy et al., 2009). Plain water intake was set as follows: one bottle of $600 \mathrm{~mL}$ water before each mealtime (breakfast, lunch and dinner) ad libitum during the intervention period.

HIIT intervention was given 3 times/week (70-85\% of HR-max) for 18 minutes each session (Eather et al., 2019). Heart rate (HR) was measured by a smartphone application. A recorded video was utilised to ease the subjects in following the HIIT movements. The HIIT training protocol was divided into three parts: warm up, four sets of 20-s body weight HIIT workout with 10-s rest (broad jumps, squat jump, switch foot jumps, and squad jumps squad) and cool down. Training intensity was gradually increased during each exercise.

The compliance of subjects towards PWI and HIIT interventions was monitored during the study. Supervision through in-person interviews was conducted to figure out what the subjects were experiencing during the interventions. Each subject consumed a total of 84 bottles of water per month, and underwent three times/week of HIIT intervention.

\section{Statistical analysis}

Data analyses were performed gradually, starting from the data collected in the field and from questionnaires, until they were ready to be analysed. The data obtained from the field or questionnaire were through several stages: editing, coding, and entry stages. Univariate analysis was performed to determine the data distribution descriptively. Mean values before and after the interventions in all ratio data (nutrient intake, nutritional status, and lipid profile) for the three intervention groups were analysed by applying paired sample $t$-test. Meanwhile, Analysis of variance (ANOVA) was utilised to compare the means of nutrient intake, nutritional 
Table 1. Subjects' characteristics based on intervention groups

\begin{tabular}{lccc}
\hline Characteristics & $P W I(n=9)$ & $H I I T(n=9)$ & $P W I+H I I T(n=9)$ \\
\hline Men/women, $n$ & $1 / 8$ & $2 / 7$ & $2 / 7$ \\
Age (year) & $19.9 \pm 0.6$ & $19.8 \pm 0.4$ & $19.5 \pm 0.9$ \\
Weight (kg) & $69.7 \pm 19.0$ & $62.6 \pm 6.5$ & $63.6 \pm 9.6$ \\
BMI $\left(\mathrm{kg} / \mathrm{m}^{2}\right)$ & $26.6 \pm 3.6$ & $25.9 \pm 2.4$ & $25.7 \pm 3.4$ \\
Percent body fat (\%) & $22.5 \pm 8.9$ & $24.6 \pm 5.6$ & $24.8 \pm 7.1$ \\
Total body water, TBW (L) & $36.0 \pm 6.5$ & $34.8 \pm 5.2$ & $35.3 \pm 7.3$ \\
Total cholesterol (mg/dL) & $180.8 \pm 30.8$ & $190.3 \pm 13.0$ & $178.7 \pm 21.8$ \\
Triglyceride (mg/dL) & $91.5 \pm 22.4$ & $84.5 \pm 32.4$ & $88.3 \pm 26$ \\
HDL-C (mg/dL) & $51.5 \pm 10.4$ & $56.8 \pm 11.0$ & $57.5 \pm 8.2$ \\
LDL-C (mg/dL) & $111.6 \pm 28.2$ & $111.0 \pm 11.5$ & $101.7 \pm 15.3$ \\
\hline Data are prese
\end{tabular}

Data are presented in mean $\pm S D$

status, and lipid profile among the three intervention groups.

\section{RESULTS}

The subjects of this study were 27 people ranging from 17-19 years old. The mean age for each group were $19.9 \pm 0.6$ years old (PWI group), 19.8 \pm 0.4 years old (HIIT group), and 19.5 \pm 0.9 years old (PWI+HIIT group), respectively. Lipid profile described that TC found in the HIIT group was higher than the others. Subjects' characteristics based on intervention groups are presented in Table 1.

Types of beverages and the amount of water intake were analysed in this study. The types of beverages analysed were plain water, carbonated drinks, electrolytes drinks, coffee and tea, juice or fruit juice, and milk. Mean consumption of plain water in the PWI, HIIT, and PWI+HIIT groups were $2300 \pm 737 \mathrm{~mL}, \quad 1752 \pm 791 \mathrm{~mL}$, and $2500 \pm 719 \mathrm{~mL}$, respectively. Water intake and energy intake from beverages in the PWI+HIIT group was higher than the other groups. Total water intake and energy intake according to types of beverages consumed are shown in Table 2 .
Percent body fat (PBF) and BMI of the PWI+HIIT group showed the most significant decrease of $-4.1 \pm 4.7 \%$ and $-0.05 \pm 3.3 \mathrm{~kg} / \mathrm{m}^{2}$. Based on ANOVA, there was no significant difference in PBF and BMI among the three groups. However, based on paired $t$-test for before and after intervention, there was a change in PBF and BMI in the PWI+HIIT group. Energy intake of the PWI group was $1964 \pm 527 \mathrm{kcal}, 1933 \pm 248 \mathrm{kcal}$ for the HIIT group, and $2002 \pm 563 \mathrm{kcal}$ for the PWI+HIIT group. Protein intake for the PWI group was $52.4 \pm 15.1 \mathrm{~g}, 50.5 \pm 14.6$ $\mathrm{g}$ for the HIIT group, and $46.2 \pm 12.5 \mathrm{~g}$ for the PWI+HIIT group. There was no significant difference in nutrient intake $(p>0.05)$.

After an eight-week intervention, it was shown that HDL-C of the PWI group significantly increased and TC of the HIIT group significantly reduced $(p<0.05)$. Compared to the other groups, PWI+HIIT group had a significant decrease in TC and TG, with improved HDL-C $(p<0.05)$. The average nutrient intake, nutritional status, and lipid profile of the subjects at baseline and after eight weeks of intervention are presented in Table 3 . After the intervention, the compliance of the three intervention groups had an 
Table 2. Water and energy intake from beverages based on intervention groups

\begin{tabular}{lcccccc}
\hline & \multicolumn{4}{c}{ Water and energy intakes from beverages } \\
\cline { 2 - 7 } \multicolumn{1}{c}{ Beverages } & $\begin{array}{c}\text { Water } \\
\text { intake } \\
\end{array}$ & $\begin{array}{c}\text { Energy } \\
\text { intake } \\
(\mathrm{m})\end{array}$ & $\begin{array}{c}\text { Water } \\
\text { intake } \\
(\mathrm{kcal})\end{array}$ & $\begin{array}{c}\text { Energy } \\
\text { intake } \\
(\text { kcal })\end{array}$ & $\begin{array}{c}\text { Water } \\
\text { intake } \\
(\mathrm{mL})\end{array}$ & $\begin{array}{c}\text { Energy } \\
\text { intake } \\
(\mathrm{kcal})\end{array}$ \\
\hline Plain water & $2300 \pm 737$ & 0 & $1752 \pm 791$ & 0 & $2500 \pm 719$ & 0 \\
Carbonated drinks & $183 \pm 173$ & $80 \pm 77$ & $94 \pm 69$ & $231 \pm 159$ & $99 \pm 73$ & $231 \pm 159$ \\
Electrolyte drinks & $244 \pm 187$ & $63 \pm 56$ & $255 \pm 195$ & $69 \pm 60$ & $220 \pm 170$ & $54 \pm 54$ \\
Coffee or tea & $110 \pm 142$ & $55 \pm 72.6$ & $95 \pm 125$ & $60 \pm 84$ & $175 \pm 170$ & $117 \pm 126$ \\
Juice or fruit juice & $100 \pm 61.2$ & $43 \pm 44$ & $120 \pm 63$ & $35 \pm 20$ & $60 \pm 84$ & $29 \pm 42$ \\
Milk & $127 \pm 148$ & $62 \pm 65$ & $105 \pm 44$ & $34 \pm 41$ & $80 \pm 71$ & $29 \pm 38$ \\
Total & $3063 \pm 798$ & $303 \pm 101$ & $2558 \pm 737$ & $292 \pm 143$ & $3262 \pm 635$ & $328 \pm 156$ \\
\hline
\end{tabular}

Data are presented in mean $\pm S D$

adherence rate of $>90 \%$ (PWI: 98.8\%; HIIT: 98.1\%; PWI + HIIT: 97.7\%).

\section{DISCUSSION}

Health experts commonly recommend consuming eight glasses of water to maintain health and well-being. Consuming more water than normally consumed at mealtimes (breakfast, lunch and dinner) under dietary recommendations can reduction in meal energy intake (Jeong, 2018). Another recommended and suggested action to maintain health and fitness is by doing physical activity. Doing physical activity for at least 150 minutes of at least moderate intensity per week is highly recommended to maintain health.

HIIT is a cardio exercise that combines high-intensity exercise with moderate or low-intensity exercise within a specific time or interval, which takes about four to six minutes on average. The duration for HIIT is very diverse, with an average of 15-20 minutes, depending on the duration of warm-up, workout, and cool-down sessions. In this study, the duration of HIIT was 18 minutes. Hence, it is preferable and favourable because it improves fitness more quickly, takes a relatively shorter time, and is more fun. HIIT is also a physical exercise that is modified for individuals with different fitness levels and special conditions, namely obesity and diabetes. It has been shown to effectively reduce the risk of injury and decrease glucose intolerance in obese women with diabetes (Madsen et al., 2015). It is one of the physical and cardio exercises that can improve nutritional status and health.

Characteristics of HIIT makes it a form of strenuous exercise; whereby its Excess of Post-Exercise Oxygen Consumption (EPOC) provides an extra $6-15 \%$ of energy expenditure during exercise (Laforgia, Withers, \& Gore, 2006). A study showed that the contribution of EPOC to facilitate weight loss can result from calorie restriction (Tucker, Angadi \& Gaesser, 2016). Results from a previous study showed that losing body weight by $5 \%$ had a positive impact on the decrease of TC and TG levels (Fayh et al., 2013). Efforts to improve nutritional status can be more effective if they are applied with a combination of diet and physical activity.

Improving nutritional status can also be done by managing food and beverage 


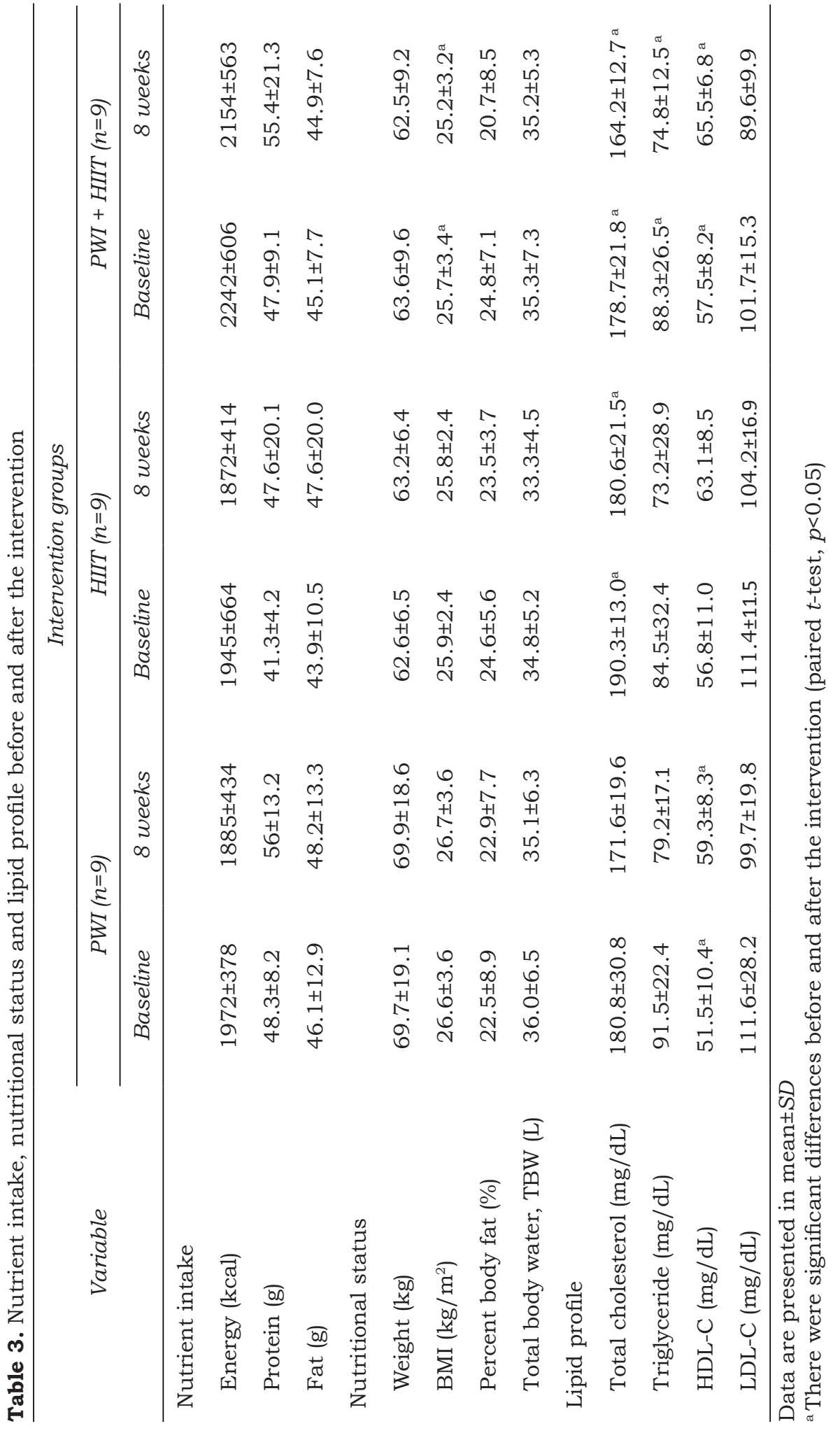


consumption. The relationship of water intake with overweight is independent, just like factors such as physical exercise, smoking status, cigarettes utilisation, and energy intake. The effect of water intake and water balance could be useful for preventing overweight and obesity (García et al., 2019). It has been shown that pre-meal plain water consumption of $500 \mathrm{~mL}$ and hypocaloric diet led to weight loss in obese adults (Davy et al., 2009). This indicates that the mechanism of water intake before each meal to control nutrient intake may potentially prevent obesity (Daniels $\&$ Popkin, 2010). Based on the results of this study, pre-meal water consumption of $600 \mathrm{~mL}$ and HIIT reduced nutrient intake by $<5 \%$. Meanwhile, the results from a previous study showed that HIIT intervention improved VLDL-C (Campbell, Wallman, \& Green, 2010). Furthermore, HIIT was also reported to be beneficial to increase HDL-C levels, improve nutritional status, and maximal oxygen uptake $\left(\mathrm{VO}_{2} \mathrm{max}\right)$ (Nalcakan, 2014).

Increased HDL occurred in all intervention groups, with the PWI group at $6.7 \pm 6.6 \mathrm{mg} / \mathrm{dL}$, HIIT group at $5.7 \pm 6.0 \mathrm{mg} / \mathrm{dL}$, and PWI+HIIT group at $6.6 \pm 6.2 \mathrm{mg} / \mathrm{dL}$. However, the PWI group and PWI+HIIT group were significantly different $(p<0.05)$. Results of a previous study showed that the HDL-C levels $(\mathrm{mg} / \mathrm{dL})$ in adolescents who were given a 12 -week intervention increased by $9.7 \%$ (mg/dL), but there were no changes in their TC levels $(\mathrm{mg} / \mathrm{dL}$ ) (Tjønna et al., 2008). Based on the review of 13 research studies regarding HIIT, HDL-C level $(\mathrm{mg} / \mathrm{dL})$ would increase after intervention if its level at baseline was very low, with a minimum duration of eight weeks intervention (Kessler et al., 2012). When compared to the results in this study, HDL-C levels was increased by $10 \%$ after a duration of eight weeks intervention.

In comparison with a study in Taiwan, it was found that aerobic exercise and badminton were also associated with higher HDL-C levels (Nassef et al., 2019). HIIT workout has been proven successful in reducing fat in the abdominal section of young women within 15 weeks (Trapp, Chisholm \& Boutcher, 2007). The results of this study were in accordance with a previous study presenting that HIIT intervention for 12 weeks in obese adolescent boys, with an intensity of 8095\% maximum heart rate, for 20 minutes could reduce total body fat, abdominal fat, and improve fitness $\left(\mathrm{VO}_{2} \max \right)$ (Heydari, Freund \& Boutcher, 2012). In fact, a study on the effect of aerobic exercise with different intensities and methods showed that HIIT was proven effective to increase aerobic fitness ( $\mathrm{VO}_{2} \max$ ) by 6-8\% (Byrd et al., 2019). Besides that, HIIT intervention was also proven effective to improve strength, cardiorespiratory fitness, and lower TG levels in physically active men (Cuddy, Ramos \& Dalleck, 2019).

However, not all HIIT interventions can improve lipid profile in the body. A previous study showed that HIIT intervention could not improve the levels of blood lipid profile (TC, TG, HDL-C, and LDL-C), but it might increase subjects' aerobic capacity. The researchers in that study explained that the weakness of their study lied in a relatively short duration of intervention (12 weeks) and small number of subjects (Ouerghi et al., 2014). If compared to the eight-week duration of this study, PWI and HIIT intervention had been able to improve the levels of lipid profile (TC, TG, and HDL-C) in the body, except for LDL-C levels. Changes in lipid profile values in the body are affected by many factors, including age, diet high in saturated fat 
and cholesterol, genetics, hormones, body weight, level of physical activity, and other diseases.

Combining various physical activities such as HIIT, endurance training, and low-intensity training is one of the strategies to maintain health and improve nutritional status. A study showed that HIIT was proven to be more effective in improving lipid profiles and keeping blood pressure in the normal range compared to other interventions (Paoli et al., 2013). A recent study has also found that water pre-loading before main meals may be effective as a weight loss strategy in adult obesity (Parretti et al., 2015). In this study, the combination of PWI + HIIT group intervention was proven to be more effective in improving the levels of lipid profile (improved $8 \mathrm{mg} /$ $\mathrm{dL}$ of HDL-C, reduced $<14.6 \mathrm{mg} / \mathrm{dL}$ of TC and $<135 \mathrm{mg} / \mathrm{dL}$ of TG) when compared to the PWI group (improved $7.8 \mathrm{mg} /$ $\mathrm{dL}$ of HDL-C) and HIIT group (reduced $9.7 \mathrm{mg} / \mathrm{dL}$ of TC). However, there was no significant difference between lipid profile among the three groups by ANOVA $(p>0.05)$.

Review of several studies on the effect of the provision of drinking water on weight loss showed that the results had not been consistent. Therefore, in future studies, it is recommended to increase the number of subjects and use a longitudinal study design so that the results can be applied to the population. This study has some weaknesses, namely the short duration of intervention, the absence of a measurement for hydration status, and the small number of subjects. Most study results focus on the process of improving nutritional status by doing exercise and following a specific diet. Therefore, health and fitness need to be maintained in optimum condition by engaging in exercise and practising healthy food habits, as well as increasing one's motivation. It must be continuously done (sustainable), especially in overweight and obese adolescents.

\section{CONCLUSION}

A combination of PWI and HIIT may be effective in improving the lipid profile of obese and overweight students. The intervention decreased the levels of TC $(\mathrm{mg} / \mathrm{dL})$ and TG $(\mathrm{mg} / \mathrm{dL})$, while improved HDL-C. For further studies, inflammatory biomarkers and other fitness components such as speed, flexibility, strength, and endurance can be added as variables.

\section{Acknowledgement}

We are grateful to the nutrition student who volunteered for this study and also Megah Stefani for her support and motivation for this study.

\section{Authors' contributions}

NAZ, principal investigator, conceived the presented idea, prepared the draft of the manuscript, developed the theory and performed the computations and wrote the paper; HAR, verified the analytical methods, analysed and interpreted the data and reviewed the manuscript; DMR, designed the model and the computational framework, analysed the data and reviewed the manuscript; MK, designed the exercise programme.

\section{Conflict of interest}

The authors have no conflicts of interest that are directly relevant to the content of this research.

\section{References}

Aronne LJ \& Isoldi KK (2007). Overweight and obesity : key components of cardiometabolic risk. Clinical Cornerstone 8(3):29-37.

Buschmann M, Steiniger J, Hille U, Tank J, Adams F, Sharma AM, Klaus S \& Luft FC (2003). Water-induced thermogenesis. J Clin Endocrinol Metab 88(12):6015-6019. https:// doi.org/10.1210/jc.2003-030780

Byrd BR, Keith J, Keeling SM, Weatherwax RM, Nolan PB, Ramos JS \& Dalleck LC (2019). Personalized moderate-intensity exercise training combined with high-intensity interval training enhances training responsiveness. Int $J$ Environ Res Public Health 16(12):2088. https://doi.org/10.3390/ijerph16122088 
Campbell L, Wallman K \& Green D (2010). The effects of intermittent exercise on physiological outcomes in an obese population: Continuous versus interval walking. $J$ Sports Sci Med 9(1):24-30.

Cuddy TF, Ramos JS \& Dalleck LC (2019). Reduced exertion high-intensity interval training is more effective at improving cardiorespiratory fitness and cardiometabolic health than traditional moderate-intensity continuous training. Int $J$ Environ Res Public Health 16(3). https://doi. org/10.3390/ijerph16030483

Daniels MC \& Popkin BM (2010). Impact of water intake on energy intake and weight status: A systematic review. Nutr Rev 68(9):505-521. https://doi.org/10.1111/ j.1753-4887.2010.00311.x

Davy BM, Dennis EA, Dengo AL, Kelly L, Davy KP, Davy BM \& Dengo AL (2009). Water consumption reduces energy intake at a breakfast meal in obese older adult. $J A m$ Diet Assoc 108(7): 1236-1239. https://doi. org/10.1016/j.jada.2008.04.013

Dennis EA, Dengo AL, Comber DL, Flack KD, Savla J, Davy KP \& Davy BM (2011). Water consumption increases weight loss during a hypocaloric diet intervention in middleaged and older adults. Obesity (Silver Spring) 23(1):1-7. https://doi.org/10.1161/ CIRCULATIONAHA.110.956839

Eather N, Riley N, Miller A, Smith V, Poole A, Vincze L, Lubans Poole AV, Lisa M, Philip JL \& David R (2019). Efficacy and feasibility of HIIT training for university students: The UniHIIT RCT. J Sci Med in Sport 22(5):596-601. https://doi.org/10.1016/j.jsams.2018.11.016

Fayh APT, Lopes AL, Da Silva AMV, ReischakOliveira Á \& Friedman R (2013). Effects of $5 \%$ weight loss through diet or diet plus exercise on cardiovascular parameters of obese: A randomized clinical trial. Eur J Nutr 52(5):1443-1450. https://doi.org/10.1007/ s00394-012-0450-1

Gaesser GA, Angadi SS \& Sawyer BJ (2011). Exercise and diet, independent of weight loss, improve cardiometabolic risk profile in overweight and obese individuals. The Physician and Sportsmedicine 39(2):87-97. https://doi.org/10.3810/psm.2011.05.1898

García AIL, Moráis-Moreno C, Samaniego-Vaesken $M$ de L, Puga AM, Partearroyo T \& VarelaMoreiras G (2019). Influence of water intake and balance on body composition in healthy young adults from Spain. Nutrients 11(8). https://doi.org/10.3390/nu11081923
Gripp F, Nava RC, Cassilhas RC, Esteves EA, Magalhães COD, Dias-Peixoto MF, de Castro MF, Amorim FT (2020). HIIT is superior than MICT on cardiometabolic health during training and detraining. Eur J Appl Physiol 121:1590172. https:/ / doi.org/ 10.1007/00421-020-04502-6

Heydari M, Freund J \& Boutcher SH (2012). The effect of high-intensity intermittent exercise on body composition of overweight young males. $J$ Obes 2012:480467 https://doi. org/ 10.1155/2012/480467

Jeong JN (2018). Effect of Pre-meal Water Consumption on Energy Intake and Satiety in Non-obese Young Adults. Clin Nutr Res 7(4):291. https://doi.org/10.7762/cnr.2018.7.4.291

Kessler HS, Sisson SB \& Short KR (2012). The potential for high-intensity interval training to reduce cardiometabolic disease risk. Sports Medicine 42(6):489-509. https://doi. org/10.2165/11630910-000000000-00000

Laforgia J, Withers RT \& Gore CJ (2006). Effects of exercise intensity and duration on the excess post-exercise oxygen consumption. $J$ Sports Sci 24(12):1247-1264. https://doi. org/10.1080/02640410600552064

Madsen SM, Thorup AC, Overgaard K \& Jeppesen PB (2015). High intensity interval training improves glycaemic control and pancreatic cell function of type 2 diabetes patients. PLOS ONE 10(8):1-24. https://doi.org/10.1371/journal. pone.0133286

Nalcakan GR (2014). The effects of sprint interval vs. continuous endurance training on physiological and metabolic adaptations in young healthy adults. J Hum Kinet 44(1):97-109. https: / / doi. org/10.2478/hukin-2014-0115

NIHRD (2018). Riset Kesehatan Dasar 2018. National Institute of Health Research and Development, Ministry of Health, Republic of Indonesia, Jakarta.

Ouerghi N, Feki M, Kaabachi N, Khammassi M, Boukorraa S \& Bouassida A (2014). Effects of a high-intensity intermittent training program on aerobic capacity and lipid profile in trained subjects. Open Access $J$ Sports Med 2014(5):243-248. https://doi.org/10.2147/ oajsm.s68701

Paoli A, Pacelli QF, Moro T, Marcolin G, Neri M, Battaglia G, Sergi Giuseppe B \& Francesco Bianco A (2013). Effects of high-intensity circuit training, low-intensity circuit training and endurance training on blood pressure and lipoproteins in middle-aged overweight men. Lipids Health Dis 12(1)1-8. https://doi. org/10.1186/1476-511X-12-131 
Parretti HM, Aveyard P, Blannin A, Clifford SJ, Coleman SJ, Roalfe A \& Daley AJ (2015). Efficacy of water preloading before main meals as a strategy for weight loss in primary care patients with obesity: RCT. Obesity 23(9):17851791. https://doi.org/10.1002/oby.21167

Popkin BM, Adair Li S \& Ng SW (2017). NOW AND THEN: The global nutrition transition: the pandemic of obesity in developing countries. Nutrients 58(1), 1-10. https://doi. org/10.1111/j.1753-4887.2011.00456.x.NOW

Stookey JD, Constant F, Gardner CD, Popkin BM, Jodi D, Constant F, Gardner C \& Barry M (2007). Replacing sweetened caloric beverages with drinking water Is associated with lower energy intake. Obesity (Silver Spring) 15(12):3013-3022.

Tjønna AE, Lee SJ, Rognmo $\varnothing$, Stølen TO, Bye A, Haram PM, Al-Share Qusai Y Skogvoll, E Slørdahl, Stig A OJ. Najjar, Sonia M \& Wisløff U (2008). Aerobic interval training versus continuous moderate exercise as a treatment for the metabolic syndrome. Circulation 118(4):346-354. https:// www.ahajournals.org/doi/10.1161/ CIRCULATIONAHA.108.772822
Trapp EG, Chisholm DJ \& Boutcher SH (2007). Metabolic response of trained and untrained women during high-intensity intermittent cycle exercise. Am J Physiol - Regul Integ Comp Physiol 293(6). https://doi.org/10.1152/ ajpregu.00780.2006

Tucker WJ, Angadi SS \& Gaesser GA (2016). Excess postexercise oxygen consumption after high-intensity and sprint interval exercise, and continuous steady-state exercise. $J$ Strength Cond Res 30(11):3090-3097. https://doi. org/10.1519/JSC.0000000000001399

WHO (2016). Obesity and overweight: Key facts. From https://www.who.int/news-room/ fact-sheets / detail/obesity-and-overweight [Retrieved March 20, 2021] 